\title{
Evaluation of Infection after Anterior Cruciate Ligament Reconstruction during a Short Period
}

\author{
Hee-June Kim, MD, Hyun-Joo Lee, MD, Jong-Chul Lee, MD, Seung-Gi Min, MD, and Hee-Soo Kyung, MD \\ Department of Orthopaedic Surgery, Kyungpook National University Hospital, Daegu, Korea
}

\begin{abstract}
Purpose: We encountered 7 cases (7.1\%) of infection (5 deep and 2 superficial) in 98 cases of anterior cruciate ligament (ACL) reconstruction using hamstring autografts in a 17 -month period. The aim of this study was to analyze the causes of infection and to introduce our treatment strategy.

Materials and Methods: We investigated the shelf-life of the fixation implants, the order of surgery, previous knee surgery, infectious pathogen, treatment of infection, and results of treatment.

Results: There was no problem with the expiration date of the fixation implants. The order of surgery was either the last or second to the last of all those performed on the same day. One patient had undergone knee surgery 8 months previously. The treatment after infection included aggressive debridement in all cases. Revision ACL reconstruction with graft removal was performed in 1 case of persistent infection with methicillin-resistant Staphylococcus aureus. All cases had satisfactory clinical results without recurrence during a mean 24.9 months of follow-up.

Conclusions: We could not verify the exact cause of the high incidence of infection during the 17-month period. However, preventive measures are important to decrease the incidence of infection after ACL reconstruction.
\end{abstract}

Keywords: Knee, Anterior cruciate ligament, Reconstruction, Infection

\section{Introduction}

Arthroscopic surgery is a standard and successful method of anterior cruciate ligament (ACL) reconstruction. Infection does not commonly occur after an arthroscopic surgery. Septic arthritis after ACL reconstruction is also a rare complication, with a reported incidence of $0.14 \%-1.70 \%{ }^{1)}$. However, immediate treatment of the infection after surgery is important to avoid complications such as damage to the cartilage and arthrofibrosis ${ }^{2)}$.

We encountered 7 cases of infection after ACL reconstruction using hamstring autografts during a short period of 17 months. The aim of this study was to analyze the causes of infection, and

Received March 14, 2016; Revised June 27, 2016;

Accepted August 22, 2016

Correspondence to: Hee-Soo Kyung, MD

Department of Orthopaedic Surgery, Kyungpook National University

Hospital, 130 Dongdeok-ro, Jung-gu, Daegu 41944, Korea

Tel: +82-53-200-5636, Fax: +82-53-422-6605

E-mail: hskyung@knu.ac.kr

This is an Open Access article distributed under the terms of the Creative Commons Attribution Non-Commercial License (http://creativecommons.org/licenses/by-nc/4.0/) which permits unrestricted non-commercial use, distribution, and reproduction in any medium, provided the original work is properly cited. share our treatment strategy.

\section{Materials and Methods}

We performed a retrospective review of 7 patients who were treated for infection after ACL reconstruction at our institution during the short period from January 2008 to May 2009. The first patient underwent surgery in January 2008, and the seventh patient in May 2009. We performed ACL reconstruction in 98 patients during this period, and 7 cases $(7.1 \%$; 6 males and 1 female; mean age, 27.9 years; age range, 16 to 44 years) of infection occurred. The surgery was performed by a single surgeon in all patients and no patient was diabetic, immunodepressed or taking steroids.

Hamstring tendon autografts were used for all patients. The femoral fixation methods for the graft were the PINN-ACL CrossPin (Linvatec, Largo, FL, USA) system with a bioabsorbable screw (BioComposite Interference Screw; Arthrex, Naples, FL, USA) in 5 cases, the CL-EndoButton (Smith \& Nephew, Andover, MA, USA) in 1 case, and both PINN-ACL CrossPin with a bioabsorbable screw and CL-EndoButton in 1 case of double bundle reconstruction (Fig. 1). Tibial fixation was performed 

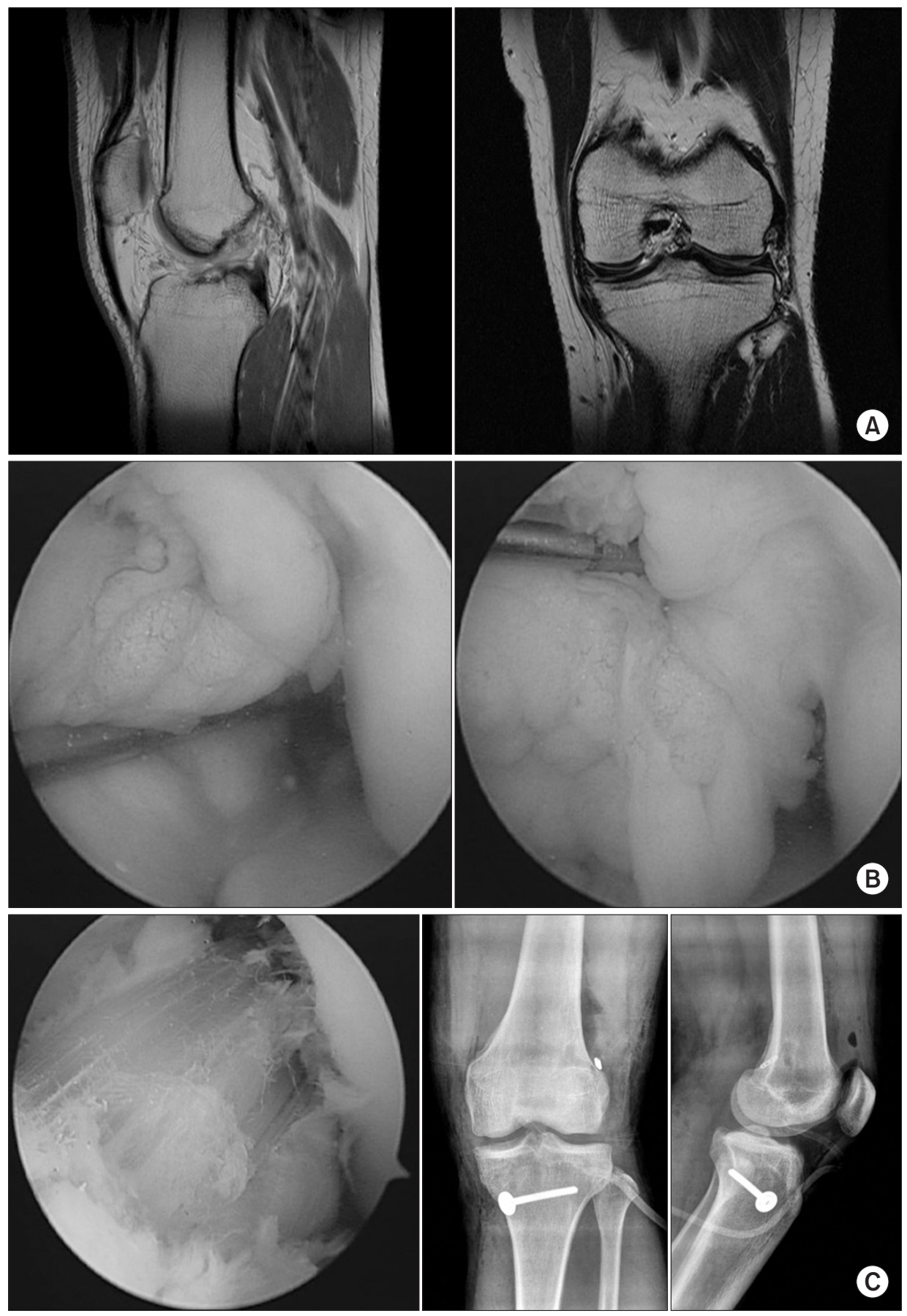

Fig. 1. An 18-year-old male patient had a twisting injury during a kicking activity. (A) Magnetic resonance imaging showed a tear of the anterior cruciate ligament (ACL) substances. (B) Arthroscopic examination also revealed a tear of the ACL substances. (C) Double bundle ACL reconstruction using a quadrupled semitendinosus tendon and a doubled gracilis tendon was performed.

by tying sutures around a metallic screw post with an additional bioabsorbable screw in all cases (Table 1). The suction drainage was removed on postoperative day 1 . Preventive intravenous antibiotics (1st generation cephalosporin) were administered from shortly before ACL reconstruction to postoperative day 2 . The patients were discharged on postoperative days $3-4$ with a followup appointment in the outpatient clinic in postoperative week 2 .

We investigated the expiration date of the absorbable fixation screw, the order of surgery, previous knee surgery, infectious pathogen, treatment of infection, and results of treatment. Postoperative evaluation was performed for the erythrocyte sedimentation rate (ESR) and C-reactive protein (CRP) level twice a week, as well as the range of motion, Tegner activity score, International Knee Documentation Committee (IKDC) subjective score, and Lysholm score. 


\section{Results}

The patients experienced swelling and pain in the knee 7-30 days after surgery in 6 cases and 89 days after surgery in 1 case. Five cases had deep joint infection with intraarticular pus, whereas 2 had a tibial side tunnel infection, defined as superficial infection. At the time of diagnosis, the mean white blood cell count was $8,536 / \mu \mathrm{L}$ (range, 4,420 to $12,030 / \mu \mathrm{L}$ ) and the mean ESR and CRP level were $48.4 \mathrm{~mm} / \mathrm{h}$ (range, 15 to $85 \mathrm{~mm} / \mathrm{h}$ ) and $9.6 \mathrm{mg} /$ $\mathrm{dL}$ (range, 0.26 to $14.51 \mathrm{mg} / \mathrm{dL}$ ), respectively.

The shelf-life of the fixation implants ranged from 2 to 3 years, and there was no problem with the expiration date of the fixation implants or the absorbable fixation screw. The order of surgery was the last (4th of 4 surgeries) in 3 cases and the second to the last (3rd of 4 surgeries or 2 nd of 3 surgeries) in 4 cases on the day of surgery. One patient had undergone an open articular reduction with screw fixation for a fracture of the lateral tibial condyle 8 months before ACL reconstruction, and ACL reconstruction was performed with concomitant removal of the fixation screw (Table 2).

In the 5 cases of deep joint infection, methicillin-resistant coag- ulase-negative Staphylococcus (MRCNS) was isolated in 3 cases, methicillin-resistant Staphylococcus aureus (MRSA) was isolated in 1 case, and both MRCNS and S. epidermidis were isolated in 1 case. In the 2 cases of superficial infection, Enterococcus faecalis was isolated in 1 case and no pathogen was isolated in 1 case.

The treatment after infection included aggressive arthroscopic debridement within 1 week after symptom development in 5 cases of deep joint infection. The treatment included arthroscopic lavage and debridement with retention of the graft in 4 cases and revision ACL reconstruction with graft removal in 1 case of persistent infection with MRSA refractory to arthroscopic debridement and intravenous antibiotics (Fig. 2). The 2 cases of superficial infection were treated with removal of the bioabsorbable screw for tibial graft fixation while retaining the post-tie screw and washer, and open debridement of the tibial infection site. Repeat debridement was performed in case of remnant infection. Intravenous first generation cephalosporin was started on admission and was changed to another antibiotic according to the antibiotic sensitivity of the isolated pathogens. The mean duration of administration of intravenous antibiotics was 29.4 days (range, 19 to 45 days).

Table 1. Characteristics of the Patients Who Developed Infection after Anterior Cruciate Ligament (ACL) Reconstruction

\begin{tabular}{ccllllc}
\hline Patients & Age $(\mathrm{yr})$ & Sex & \multicolumn{1}{c}{ Graft } & Bundle & \multicolumn{1}{c}{ Femoral fixation } & Tibial fixation \\
\hline 1 & 44 & Male & Autologous HT & Single & PINN-ACL CrossPin+BS & PT+BS \\
2 & 18 & Male & Autologous HT & Double & PINN-ACL CrossPin+BS, EndoButton & PT+BS \\
3 & 40 & Male & Autologous HT & Single & PINN-ACL CrossPin+BS & PT+BS \\
4 & 34 & Male & Autologous HT & Single & PINN-ACL CrossPin+BS & PT+BS \\
5 & 19 & Male & Autologous HT & Single & PINN-ACL CrossPin+BS & PT+BS \\
6 & 24 & Female & Autologous HT & Single & PINN-ACL CrossPin+BS & PT+BS \\
7 & 16 & Male & Autologous HT & Single & EndoButton & PT+BS \\
\hline
\end{tabular}

HT: hamstring tendon, BS: bioabsorbable screw, PT: post-tie.

Table 2. Characteristics and Findings in 7 Cases of Infection after Anterior Cruciate Ligament Reconstruction

\begin{tabular}{|c|c|c|c|c|c|c|c|c|}
\hline Patients & Infection type & $\begin{array}{l}\text { Time to } \\
\text { presentation } \\
\text { (days after } \\
\text { operation) }\end{array}$ & $\begin{array}{l}\text { Time to } \\
\text { surgery } \\
\text { (days after } \\
\text { symptom) }\end{array}$ & $\begin{array}{c}\text { WBC } \\
\left(10^{3} / \mu \mathrm{L}\right)\end{array}$ & $\begin{array}{c}\text { ESR } \\
(\mathrm{mm} / \mathrm{h})\end{array}$ & $\begin{array}{c}\text { CRP } \\
(\mathrm{mg} / \mathrm{dL})\end{array}$ & $\begin{array}{l}\text { Order of } \\
\text { surgery }\end{array}$ & $\begin{array}{c}\text { Previous } \\
\text { knee surgery }\end{array}$ \\
\hline 1 & Deep joint infection & 15 & 6 & 9.52 & 66 & 21.4 & $4 / 4$ & Yes \\
\hline 2 & Deep joint infection & 7 & 7 & 7.04 & 72 & 19.1 & $4 / 4$ & No \\
\hline 3 & Deep joint infection & 10 & 5 & 8.46 & 28 & 6.7 & $2 / 3$ & No \\
\hline 4 & Deep joint infection & 30 & 1 & 7.79 & 85 & 14.5 & $3 / 4$ & No \\
\hline 5 & Superficial infection & 10 & 7 & 12.03 & 28 & 4.0 & $3 / 4$ & No \\
\hline 6 & Deep joint infection & 11 & 2 & 10.49 & 45 & 0.9 & $3 / 4$ & No \\
\hline 7 & Superficial infection & 89 & 1 & 4.42 & 15 & 0.3 & $4 / 4$ & No \\
\hline
\end{tabular}

WBC: peripheral white blood cell count, ESR: erythrocyte sedimentation rate, CRP: C-reactive protein. 

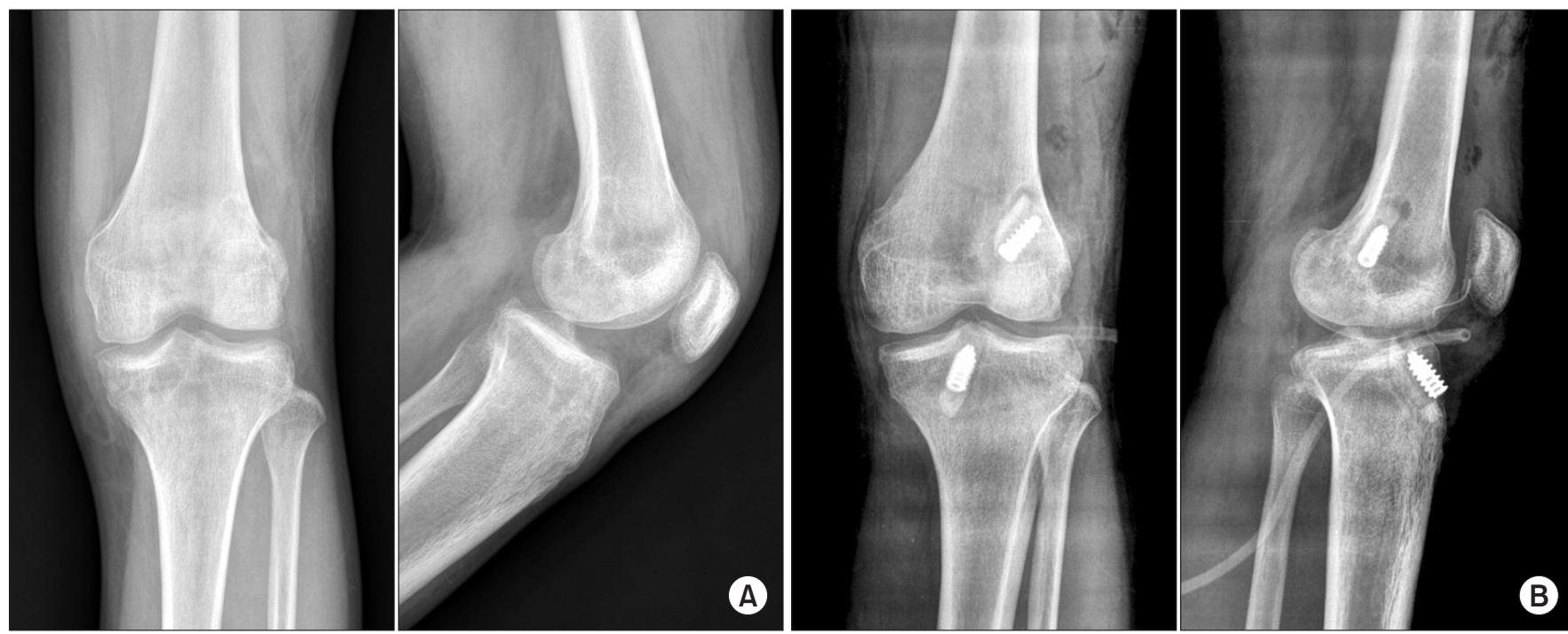

Fig. 2. Seven days after anterior cruciate ligament (ACL) reconstruction, the patient had knee pain with fever and chills. Seven days after symptom development, the patient visited the outpatient clinic and arthroscopic debridement was performed. However, methicillin-resistant Staphylococcus aureus infection persisted despite treatment. (A) Therefore, 29 days after the ACL reconstruction, arthroscopic debridement was performed again with removal of the graft and hardware. (B) After infection control, revision ACL reconstruction with bone-patellar tendon-bone allograft was performed. At the 26-month follow-up, the patient recovered nearly all activity and motion, and instability was not evaluated.

Table 3. Treatment of Infection and Results

\begin{tabular}{|c|c|c|c|c|c|c|c|c|c|c|}
\hline Patients & Organism & $\begin{array}{l}\text { Definitive } \\
\text { antibiotics }\end{array}$ & $\begin{array}{c}\text { Intravenous } \\
\text { antibiotics } \\
\text { duration (day) }\end{array}$ & $\begin{array}{l}\text { Operative } \\
\text { treatment }\end{array}$ & $\begin{array}{c}\text { No. of } \\
\text { procedures } \\
\text { for infection }\end{array}$ & $\begin{array}{c}\mathrm{F} / \mathrm{U} \\
\text { period } \\
(\mathrm{mo})\end{array}$ & $\mathrm{ROM}\left({ }^{\circ}\right)$ & $\begin{array}{l}\text { Tegner } \\
\text { activity } \\
\text { score }\end{array}$ & $\begin{array}{l}\text { IKDC } \\
\text { score }\end{array}$ & $\begin{array}{c}\text { Lysholm } \\
\text { score }\end{array}$ \\
\hline 1 & MRCNS & $\begin{array}{l}\text { Teicoplanin, } \\
\text { ciprofloxacin }\end{array}$ & 20 & $\mathrm{AD}$ & 1 & 12 & 125 & 6 & 88.5 & 93 \\
\hline 2 & MRSA & $\begin{array}{l}\text { Vancomycin, } \\
\text { ciprofloxacin }\end{array}$ & 26 & $\begin{array}{l}\text { AD \& graft } \\
\text { removal+ACL } \\
\text { revision } \\
\text { reconstruction }\end{array}$ & 2 & 26 & 130 & 6 & 88.5 & 94 \\
\hline 3 & MRCNS & $\begin{array}{l}\text { Vancomycin, } \\
\text { cefazolin }\end{array}$ & 45 & $\mathrm{AD}$ & 1 & 12 & 120 & 7 & 90.8 & 95 \\
\hline 4 & MRCNS & $\begin{array}{l}\text { Teicoplanin, } \\
\text { ciprofloxacin }\end{array}$ & 19 & $\mathrm{AD}$ & 1 & 12 & 135 & 5 & 79.3 & 88 \\
\hline 5 & $\mathrm{EF}$ & $\begin{array}{l}\text { Ampicillin, } \\
\text { sulbactam }\end{array}$ & 28 & OD & 3 & 36 & 135 & 7 & 96.6 & 96 \\
\hline 6 & MRCNS+SE & $\begin{array}{l}\text { Vancomycin, } \\
\text { ciprofloxacin }\end{array}$ & 38 & $\mathrm{AD}$ & 1 & 26 & 130 & 7 & 87.4 & 90 \\
\hline \multirow[t]{2}{*}{7} & No growth & Cefazolin & 30 & OD & 2 & 50 & 130 & 6 & 88.5 & 90 \\
\hline & Average & & 29.4 & & & 24.9 & 129.3 & 6.3 & 88.5 & 92.3 \\
\hline
\end{tabular}

F/U: follow-up, ROM: range of motion, IKDC: International Knee Documentation Committee, MRCNS: methicillin-resistant coagulase-negative Staphylococcus, AD: arthroscopic debridement, MRSA: methicillin-resistant Staphylococcus aureus, ACL: anterior cruciate ligament, EF: Enterococcus faecalis, OD: open debridement, SE: Staphylococcus epidermidis.

In all cases, the results were satisfactory at a mean of 24.9 months (range, 12 to 50 months) of follow-up. The symptoms of infection disappeared and the ESR and CRP levels normalized in 4 weeks. At the final follow-up, the mean range of motion of the knee was $129.3^{\circ}$ (range, $120^{\circ}$ to $140^{\circ}$ ) and the mean Tegner activity score was 6.29 (range, 5 to 7). The mean IKDC subjec- 
tive score and Lysholm score were 88.51 (range, 87.4 to 96.6) and 92.29 (range, 88 to 96 ), respectively (Table 3 ). No patient had recurrence of infection after treatment.

\section{Discussion}

In this study, good clinical results were obtained after treatment of the 7 cases (7.1\%) of infection that occurred within 17 months after ACL reconstruction at our institution. In cases of deep joint infection, arthroscopic debridement yielded good results, except in 1 case that was infected with MRSA and had to undergo revision ACL reconstruction. However, we could not verify the exact cause of the high incidence of infection that occurred during this short period.

Some authors have reported their clinical experiences with septic arthritis of the knee after ACL reconstruction. Van Tongel et al. ${ }^{1)}$ reported postoperative septic arthritis occurred in 9 $(0.51 \%)$ of 1,736 patients during a period of 10 years. They obtained good results by performing urgent extensive arthroscopic debridement with antibiotic therapy and repeat debridement if there was no response. Judd et al. ${ }^{3)}$ reported there were 11 cases (2.6\%) of infection within 3 years after 418 cases of ACL reconstruction, and these were associated with previous knee surgery. They reported that timely initiation of treatment including joint lavage, debridement, and antibiotics was essential for successful treatment. Schollin-Borg et al. ${ }^{4)}$ noted postoperative septic arthritis in 10 (1.7\%) out of 575 patients who had undergone ACL reconstruction during a period of 4 years. They reported clinical results in these patients were inferior to those in patients with uncomplicated reconstruction, and observed that surgical instruments might be a source of contamination even after sterilization procedures.

There are multiple factors that could cause infection after arthroscopic ACL reconstruction: previous knee surgery, contamination during preparation of the graft, incomplete sterilization of surgical instruments, implant for graft fixation, and environmental contamination of surgical equipment or hospital material ${ }^{3-6)}$.

Previous knee surgery or additional procedures during ACL reconstruction could be risk factors for infection because of increased operative time, additional incisions, or increased foreign body load ${ }^{2,3,7}$. In our study, 1 patient with deep infection had undergone an open articular reduction with screw fixation for a fracture of the lateral tibial condyle before ACL reconstruction. In addition, ACL reconstruction was performed with concomitant removal of the fixation screw, which required an additional 3 minutes. In this patient, previous screw fixation surgery could have been the cause of infection due to an additional incision and foreign body.

Judd et al. ${ }^{3)}$ reported that hamstring grafts were associated with a higher incidence of infection. Soft tissue injuries involved in harvesting the tendons and creating a tibial tunnel and the use of an additional metallic post, washer, and braided sutures in subcutaneous position could be the causes of wound complications. Hantes et al. ${ }^{8)}$ and Gavriilidis et al. ${ }^{9)}$ reported a $10 \%$ infection rate associated with intraoperative graft contamination, especially in the autologous hamstring tendon. Based on these reports, the hamstring tendon used in all cases in our study could have been the source of infection.

Tuman et al. ${ }^{10)}$ reported that inappropriate sterilization of a fully assembled complex tendon-harvesting instrument could be a cause of postoperative infection. In our study, the tendonharvesting instrument was a single tube tendon striper, which was not constructed with a complex geometry.

Fixation methods used for the grafts could also be the cause of infection. So, we checked the expiration date of the fixation implant on the label retrospectively. However, there was no problem with the expiration date of the fixation implant or absorbable fixation screw.

The order of surgery could be associated with the cause of infection. In this study, all ACL reconstructions were the last or second to the last at the end of the day. Therefore, the instruments for arthroscopic surgery were sterilized in the interval between surgeries performed on the day due to the lack of instruments for several arthroscopies. Instruments sterilized by soaking in a 2\% glutaraldehyde solution (Cidex; Johnson and Johnson Medical Inc., Arlington, TX, USA) during the interval of the surgery might increase the risk of infection compared to newly sterilized instruments. This could have been the cause of infection, but this was not proven in this study.

The scrub nurse who usually supervised instrument sterilization was changed during the 17 -month period. Sterilization of all the instruments, including the arthroscope and the cannulated reamer, was previously performed and supervised by this nurse. We were aware that this could cause infection after ACL reconstruction; therefore, reeducation and training regarding sterilization of instruments were imparted to the new scrub nurse and other support staff.

Different treatment options are associated with graft retention. Indications for graft removal after infection in ACL reconstruction include unstable grafts necessitating clinical examination or arthroscopic evaluation and grafts impregnated with tenacious and thick exudation that cannot be removed without damaging 
the graft and delaying treatment after the onset of symptoms ${ }^{1,11,12)}$. In our study, only 1 case underwent revision ACL reconstruction after graft removal and infection control for persistent infection refractory to treatment. The other cases of infection were treated with arthroscopic lavage and graft retention.

Treatment of infection can be accomplished by arthroscopic and open surgical wound irrigation and debridement and 4-6 weeks of antibiotic therapy ${ }^{2}$. In our study, 5 cases of septic arthritis were treated using arthroscopic irrigation and 2 cases of superficial tibial infection were treated using open surgical wound irrigation, combined with intravenous antibiotics for about 4 weeks (average, 29.4 days). Aggressive surgical debridement combined with proper antibiotics according to the isolated pathogen is thought to be the key for effective treatment.

The possible causes of infection after ACL reconstruction in our institution include the employment of a new scrub nurse who supervises instrument sterilization, contamination during preparation of hamstring grafts, and sterilization through soaking in a Cidex solution during the interval between surgeries. Therefore, we have taken every measure to prevent infection after ACL reconstruction: 1) the use of simple graft fixation instruments (CL-EndoButton) rather than complex instruments (PINN-ACL CrossPin); 2) thorough surgical draping; 3) drain insertion at the donor site; 4) the use of new, sterilized stockinette wrapping from the toe to minimize incision at the hamstring tendon harvest site before graft tensioning; 5) arranging the order of surgery to be the first arthroscopic operation for securing sufficient time for instrument cleaning; and 6) training of staff regarding instrument cleaning, especially the cannulated reamer. After implementation of these preventive measures, we have not encountered an infection in the 350 cases of ACL reconstruction performed at our institution during a period of 6 years.

The limitations of this study include the small number of patients, retrospective study design, and lack of a control group. Future studies should include a larger number of patients and a control group for comparison.

\section{Conclusions}

We could not verify the exact cause of the high incidence of infection that occurred after ACL reconstruction during a short period. However, we believe that efforts to prevent infection is important to decrease the incidence after ACL reconstruction. Furthermore, satisfactory clinical results can be achieved by appropriate and aggressive treatment of early infection after ACL reconstruction.

\section{Conflict of Interest}

No potential conflict of interest relevant to this article was reported.

\section{References}

1. Van Tongel A, Stuyck J, Bellemans J, Vandenneucker H. Septic arthritis after arthroscopic anterior cruciate ligament reconstruction: a retrospective analysis of incidence, management and outcome. Am J Sports Med. 2007;35:1059-63.

2. Mouzopoulos G, Fotopoulos VC, Tzurbakis M. Septic knee arthritis following ACL reconstruction: a systematic review. Knee Surg Sports Traumatol Arthrosc. 2009;17:1033-42.

3. Judd D, Bottoni C, Kim D, Burke M, Hooker S. Infections following arthroscopic anterior cruciate ligament reconstruction. Arthroscopy. 2006;22:375-84.

4. Schollin-Borg M, Michaelsson K, Rahme H. Presentation, outcome, and cause of septic arthritis after anterior cruciate ligament reconstruction: a case control study. Arthroscopy. 2003;19:941-7.

5. Viola R, Marzano N, Vianello R. An unusual epidemic of Staphylococcus-negative infections involving anterior cruciate ligament reconstruction with salvage of the graft and function. Arthroscopy. 2000;16:173-7.

6. Kyung HS, Baek SG, Lee BJ, Lee CH. Single-bundle anterior cruciate ligament reconstruction with semitendinosus tendon using the PINN-ACL CrossPin system: minimum 4-year follow-up. Knee Surg Relat Res. 2015;27:43-8.

7. Williams RJ 3rd, Laurencin CT, Warren RF, Speciale AC, Brause BD, O’Brien S. Septic arthritis after arthroscopic anterior cruciate ligament reconstruction. Diagnosis and management. Am J Sports Med. 1997;25:261-7.

8. Hantes ME, Basdekis GK, Varitimidis SE, Giotikas D, Petinaki E, Malizos KN. Autograft contamination during preparation for anterior cruciate ligament reconstruction. J Bone Joint Surg Am. 2008;90:760-4.

9. Gavriilidis I, Pakos EE, Wipfler B, Benetos IS, Paessler HH. Intra-operative hamstring tendon graft contamination in anterior cruciate ligament reconstruction. Knee Surg Sports Traumatol Arthrosc. 2009;17:1043-7.

10. Tuman J, Diduch DR, Baumfeld JA, Rubino LJ, Hart JM. Joint infection unique to hamstring tendon harvester used during anterior cruciate ligament reconstruction surgery. Arthroscopy. 2008;24:618-20.

11. Indelli PF, Dillingham M, Fanton G, Schurman DJ. Septic 
Knee Surg Relat Res, Vol. 29, No. 1, Mar. 201751

arthritis in postoperative anterior cruciate ligament reconstruction. Clin Orthop Relat Res. 2002;(398):182-8.

12. Schulz AP, Gotze S, Schmidt HG, Jurgens C, Faschingbauer
M. Septic arthritis of the knee after anterior cruciate ligament surgery: a stage-adapted treatment regimen. Am J Sports Med. 2007;35:1064-9. 